DOI: https://doi.org/10.24867/02AM09Dacevic

\title{
ODREĐIVANJE KOEFICIJENTA TRENJA METODOM SLOBODNOG SABIJANJA KONUSNOG PRSTENA
}

\section{FRICTION COEFFICIENT DETERMINATION BY CONICAL RING UPSETTING}

\author{
Nemanja Dačević, Marko Vilotić, Fakultet tehničkih nauka, Novi Sad
}

\section{Oblast - MAŠINSTVO}

Kratak sadržaj - U radu je prikazan celokupan postupak određivanja vrednosti koeficijenta trenja metodom slobodnog sabijanja konusnog prstena u uslovima hladne obrade sa podmazivanjem uljem za materijal uzorka C45E.

Ključne reči: Koeficijent trenja, kalibracione krive, konusni prsten, sabijanje, numerička simulacija

Abstract - In this paper, a complete procedure of determination a friction coefficient using a conical ring upsetting test is presented. Friction coefficient is determined for cold upsetting process with oil lubrication for material of conical rings steel C45E.

Keywords: Friction coefficient, calibration curves, conical ring, upsetting, numerical simulation

\section{UVOD}

U postupcima plastičnim deformisanjem veličina kontaktnog trenja jedan je od odlučujućih faktora od kojih će zavisiti efikasnost projektovanog procesa i kvalitet dobijenog proizvoda. Kvantitativno određivanje kontaktnog trenja u obradama deformisanjem najčešće se vrši eksperimentalnim putem merenjem određenih pokazatelja veličine kontaktnog trenja [1,2]. U ovom radu prikazano je određivanje koeficijenta trenja metodom slobodnog sabijanja konusnog prstena u slučaju hladne zapreminske obrade sa podmazivanjem za materijal obratka C45E.

\section{METODA SLOBODNOG SABIJANJA KONUSNOG PRSTENA}

U zapreminskoj obradi plastičnim deformisanjem vrednost koeficijenta trenja najčešće se određuje eksperimentalnim putem. Eksperimentalne metode možemo da podelimo na direktne i indirektne metode. Direktne metode za određivanje veličine koeficijenta trenja podrazumevaju eksperimentalno merenje lokalne sile trenja ili nekih drugih pokazatelja u zavisnosti od primenjene metode $i$ vrste obrade, dok indirektne metode podrazumevaju praćenje određenih geometrijskih veličina u uslovima podeljenog tečenja materijala.

Neke od najčešće primenjivanih indirektnih metoda su: metoda slobodnog sabijanja prstena, metoda konusnog pritiskivača, metoda slobodnog sabijanja konusnog prstena, metoda sabijanja dugačke lamele i tako dalje [3].

\footnotetext{
NAPOMENA:

Ovaj rad proistekao je iz master rada čiji mentor je bio dr Dragiša Vilotić, red. prof.
}

Metoda slobodnog sabijanja konusnog prstena predstavlja varijaciju metode slobodnog sabijanja prstena razvijenu $\mathrm{s}$ ciljem prevazilaženja njenih nedostataka i povećanja tačnosti pri određivanju većih vrednosti koeficijenta trenja [4]. Osnovnu prednost ove metode predstavlja promenljiva veličina ugla konusa $\alpha$. Ugao konusa najčešće se kreće $u$ granicama između $10^{\circ}$ i $20^{\circ}$. Pravilnim izborom veličine ugla konusa, ovom metodom moguće je eliminisati pojavu statičkog trenja i lepljenja materijala uzorka za alat, i na taj način obezbediti skoro ravnomernu brzinu tečenja materijala u radijalnom pravcu na kontaktnoj površini, pri bilo kojoj veličini koeficijenta trenja. Takođe, pri različitim vrednostima ugla konusa, menja se i osetljivost metode na različite veličine koeficijenta trenja. Primenom uzoraka sa većim uglom konusa postiže se veća osetljivost metode na veće vrednosti koeficijenta trenja, i obrnuto $[4,5]$.

Na slici 1. prikazana je skica uzorka za metodu slobodnog sabijanja konusnog prstena pre i nakon procesa sabijanja.

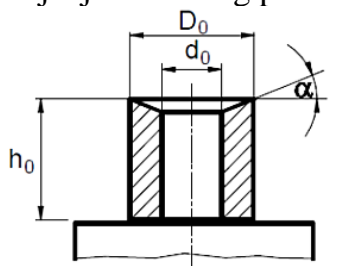

a)

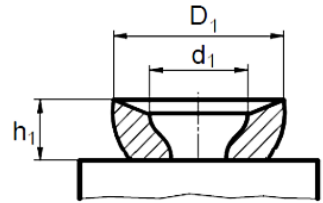

b)
Slika 1. Uzorak za metodu slobodnog sabijanja konusnog prstena [4] a) pre sabijanja b) nakon sabijanja

Uzorak sa konusnom kontaktnom površinom, prikazan na slici 1a, postavlja se na donji ravni alat i zatim sabija gornjim konusnim alatatom. Koeficijent trenja određuje se na osnovu promene dimenzija visine $\mathrm{h}$ i prečnika $\mathrm{D}$ nakon sabijanja u odnosu na početne vrednosti. Pri većim koeficijentima trenja radijalno tečenje materijala biće manje, odnosno promena prečnika $\mathrm{D}$ biće manja, i obrnuto pri manjim koeficijentima trenja. $\mathrm{Na}$ osnovu rezultata merenja izračunava se relativna promena visine $\mathrm{i}$ prečnika nakon deformisanja u odnosu na početne vrednosti i dobijena vrednost se unosi na etalon dijagram za određivanje koeficijenta trenja. Etalon dijagram za ovu metodu, usled kompleksnosti geometrije uzorka, moguće je dobiti isključivo primenom numeričke simulacije sabijanja uzorka variranjem koeficijenta trenja.

Osnovni nedostaci primene ove metode jesu viša cena izrade uzoraka i odgovarajućih alata kao i pojava nižih vrednosti kontaktnih napona usled konusne kontaktne površine. Takođe, pojava nesaosnosti konusnog prstena i alata pri pozicioniranju negativno utiče na aksijalnu simetriju uzorka nakon sabijanja, što može dovesti do 
nesigurnosti pri određivanju koeficijenta trenja s obzirom da je vrednost prečnika uzorka nakon deformisanja glavni pokazatelj kontaktnih uslova [4,5].

\section{EKSPERIMENTALNA ISTRAŽIVANJA}

Eksperiment sabijanja konusnih prstenova sastoji se u sabijanju pet uzoraka ugla konusa $8^{\circ} 30^{\prime}$ i pet uzoraka ugla konusa $15^{\circ}$ pomoću odgovarajućih alata. Umesto, uobičajenog inkrementalnog sabijanja jednog uzorka za dobijanje potrebnih promena dimenzija, primenom više uzoraka za sabijanje pri različitom hodu alata izbegava se neophodno podmazivanje nakon svakog inkrementa i remećenje sloja sredstva za podmazivanje.

Kao sredstva za podmazivanje primenjivani su:

- konusna kontaktna površina - ulje za hladno

oblikovanje metala „Modriča“

- ravna kontaktna poršina - stearinska kiselina

Pretpostavlja se da je sloj sredstva za podmazivanje ujednačen po celoj kontaknoj površini i identičan na svakom uzorku. Važi kako za ulje, tako i za stearinsku kiselinu kao primenjivana sredstva za podmazivanje.

Za sabijanje uzoraka korišćena je hidraulična presa Sack\&Kiesselbach nominalne sile 6,3 MN. Sabijanje uzoraka izvršeno je pri brzini deformisanja od $1 \mathrm{~mm} / \mathrm{min}$

$\mathrm{Na}$ slici 2. prikazani su uzorci ugla konusa $8^{\circ} 30^{\prime}$ nakon sabijanja, dok su na slici 3. prikazani uzorci ugla konusa $15^{\circ}$. Uzorci oznaka 1-8 i 1-15 sabijani su do dostizanja hoda alata od $1 \mathrm{~mm}$. Pri sabijanju svakog sledećeg uzorka hod alata je povećavan za po $1 \mathrm{~mm}$, sve do dostizanja maksimalnog hoda alata od $5 \mathrm{~mm}$ pri sabijanju poslednjih uzoraka, oznaka 5-8 i 5-15.

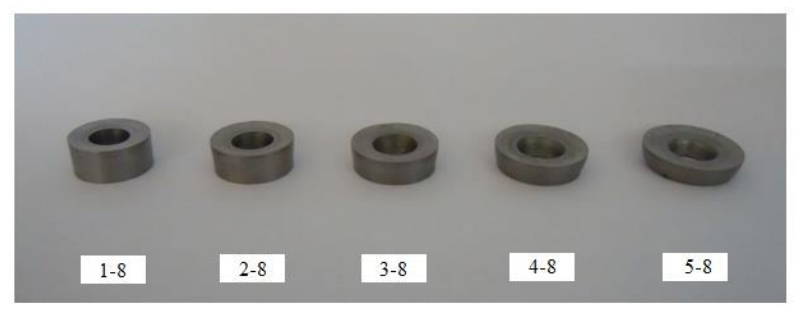

Slika 2. Uzorci ugla konusa $8^{\circ} 30^{\prime}$ nakon sabijanja

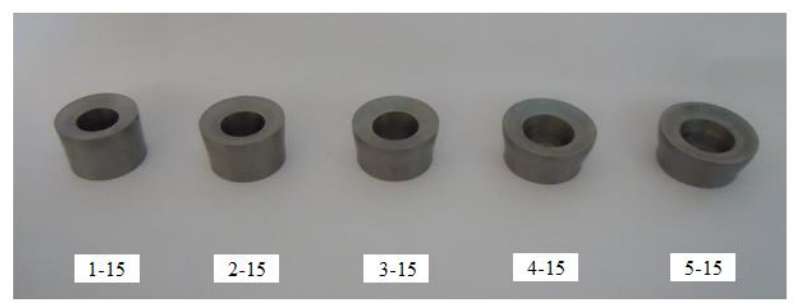

Slika 3. Uzorci ugla konusa $15^{\circ}$ nakon sabijanja

Za merenje dimenzija uzoraka pre i nakon procesa sabijanja korišćeno je digitalno pomično kljunasto merilo tačnosti $0,01 \mathrm{~mm}$. S obzirom na veliki uticaj nesaosnosti uzoraka i alata na dimenzije uzoraka nakon sabijanja, a samim tim i na tačnost dobijene vrednosti koeficijenta trenja, merenje potrebnih dimenzija izvršeno je u četiri pozicije, a kao merodavna veličina korišćena je izračunata srednja vrednost izvršenih merenja.

Na osnovu izračunatih srednjih vrednosti prečnika D i visine h uzoraka nakon sabijanja, izračunate su relativne promene prečnika $\mathrm{i}$ visine, $\mathrm{i}$ formirane krive za procenu koeficijenta trenja, prikazane na slici 4. za uzorke ugla konusa $8^{\circ} 30^{\prime}$, i na slici 5 . za uzorke ugla konusa $15^{\circ}$.

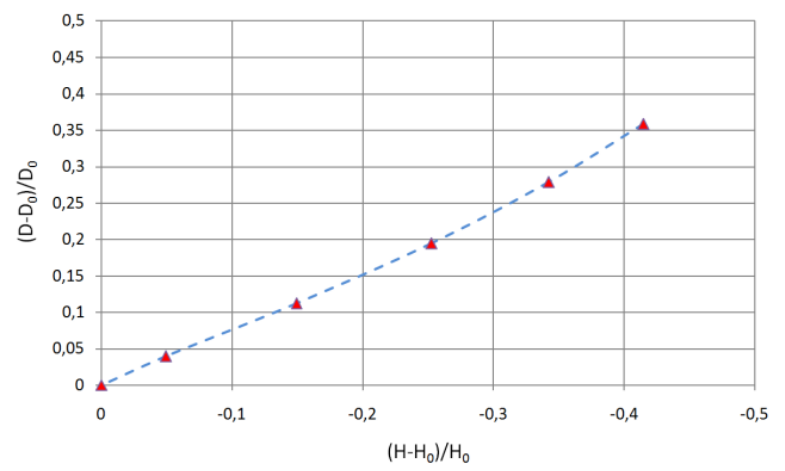

Slika 4. Kriva relativne promene visine i prečnika uzorka ugla konusa $8^{\circ} 30^{\prime}$

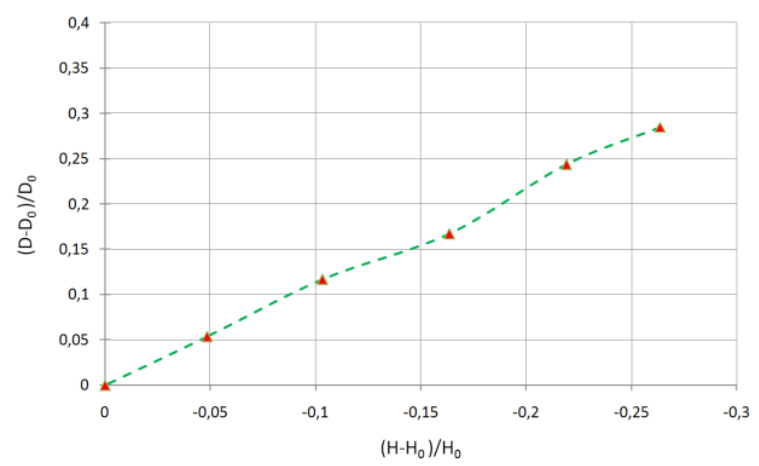

Slika 5. Kriva relativne promene visine i prečnika uzorka ugla konusa $15^{\circ}$

\section{DOBIJANJE ETALON DIJAGRAMA POMOĆU NUMERIČKE SIMULACIJE}

Etalon dijagrami za određivanje koeficijenta trenja predstavljaju skup kalibracionih krivih, gde svakoj kalibracionoj krivoj odgovara određena vrednost koeficijenta trenja.

Kalibracione krive za određivanje koeficijenta trenja metodom slobodnog sabijanja konusnog prstena moguće je dobiti primenom numeričke simulacije, i u tu svrhu korišćen je programski paket Simufact.Forming 12.

Definisanje materijala za potrebe simulacije izvršeno je manuelno. Kriva tečenja materijala C45E određena je eksperimentalnim putem metodom Rastegajeva i za potrebe simulacije korišćen je njen analitički oblik:

$$
\mathrm{K}=289,671+757,0366 \cdot \phi^{0,337698}
$$

Ostali podaci o materijalu korišćeni za potrebe simulacije dati su u tabeli 1 .

Tabela 1. Karakteristike materijala C45E

\begin{tabular}{|l|c|}
\hline Modul elastičnosti $[\mathrm{MPa}]$ & 210000 \\
\hline Gustina materijala $\left[\mathrm{kg} / \mathrm{m}^{3}\right]$ & 7800 \\
\hline Poisson-ov koeficijent & 0,33 \\
\hline
\end{tabular}

Primenjeni alati modelovani su kao apsolutno kruta tela usled čega nije potrebno izvršiti izbor materijala za iste.

Kao i pri eksperimentalnom istraživanju, i u simulaciji je korišćena hidraulična presa sa konstantnom brzinom kretanja alata od $1 \mathrm{~mm} / \mathrm{min}$.

Definisanje kontaknog trenja izvršeno je pomoću Columbovog modela trenja. Izvršene su simulacije za vrednosti ko- 
eficijenata trenja za konusnu kontaktnu površinu od $\mu=0,00$ do $\mu=0,50 \mathrm{u}$ razmacima po 0,05 . Za ravnu kontaktnu površinu, u svakoj simulaciji, korišćena je vrednost koeficijenta trenja $\mu=0,012$.

S obzirom da su i alat i uzorak rotaciono simetrični, kako bi se smanjilo vreme trajanja simulacije bez gubitka na tačnosti rezultata, umesto 3D simulacije, korišćena je 2D simulacija.

Za diskretizaciju modela na mrežu konačnih elemenata, kao konačni element izabran je kvadratni konačni element sa četiri čvora. Formiranje mreže konačnih elemenata izvršeno je na osnovu veličine konačnog elementa kako bi se obezbedila što približnija tačnost rezultata pri sabijanju uzoraka ugla konusa $8^{\circ} 30^{\prime}$ i uzoraka ugla konusa $15^{\circ}$. Veličina konačnog elementa definisana je dužinom između dva susedna čvora, i u ovom slučaju iznosi $0,16 \mathrm{~mm}$.

Sve simulacije sabijanja konusnih prstenova podešene su tako da kao izlaz pružaju deset rezultata do dostizanja hoda alata od $5 \mathrm{~mm}$. S obzirom da je podešen broj rezultata koje softver beleži deset, kalibracione krive sastojaće se od deset parova vrednosti relativne promene visine $\mathrm{i}$ prečnika uzoraka.

Na slici 6. prikazan je dobijeni etalon dijagram za uzorak ugla konusa $8^{\circ} 30^{\prime}$, dok je na slici 7. prikazan dobijeni etalon dijagram za uzorak ugla konusa $15^{\circ}$.

Poređenje ova dva etalon dijagrama, za vrednosti ugla konusa $8^{\circ} 30^{\prime}$ i $15^{\circ}$, zaključuje se da su uzorci ugla konusa $8^{\circ} 30^{\prime}$ pogodniji pri određivanjukoeficijenata trenja ugranicama od $\mu=0,10$ do $\mu=0,20$, dok uzorci ugla konusa $15^{\circ}$ pružaju najveću osetljivost pri određivanju većih vrednosti koeficijenata trenja, u granicama od $\mu=0,20$ do $\mu=0,30$.

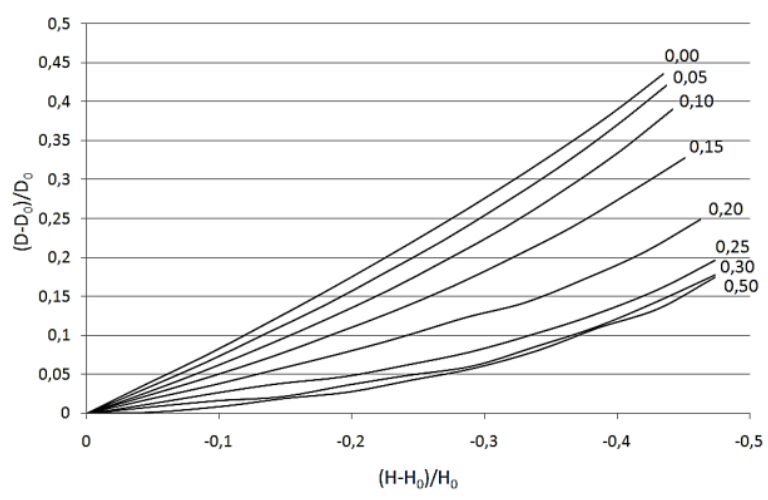

Slika 6. Etalon dijagram za određivanje koeficijenta trenja za ugao konusa $8^{\circ} 30^{\prime}$

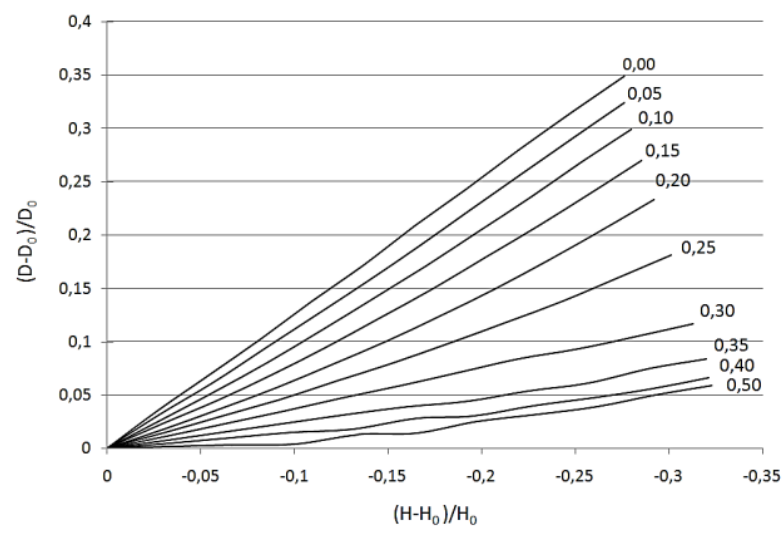

Slika 7. Etalon dijagram za određivanje koeficijenta trenja za ugao konusa $15^{\circ}$

\section{ODREĐIVANJE KOEFICIJENTA TRENJA}

Određivanje vrednosti koeficijenta trenja izvršeno je komparacijom eksperimentalno dobijene krive za uzorke ugla konusa $8^{\circ} 30^{\prime}$ i $15^{\circ}$ sa odgovarajućim etalon dijagramom. Za vrednost koeficijenta trenja uzima se ona vrednost koja odgovara kalibracionoj krivoj sa najboljim preklapanjem sa eksperimentalno dobijenom tačkom pri ostvarenoj najvećoj deformaciji.

Poređenje eksperimentalno dobijene krive sa etalon dijagramom za ugao konusa $8^{\circ} 30^{\prime}$ prikazano je na slici 8 , sa koje se vidi da se vrednost koeficijenta trenja nalazi u granicama od $\mu=0,05$ do $\mu=0,10$. Kako bi se koeficijent trenja što bolje procenio, izvršene su dodatne simulacije za vrednosti koeficijenta trenja iz datog raspona. Najbolje podudaranje eksperimentalno dobijene tačke sa kalibracionom krivom dobijeno je pri vrednost koeficijenta trenja $\mu=0,095$, kao što je prikazano na slici 9 .

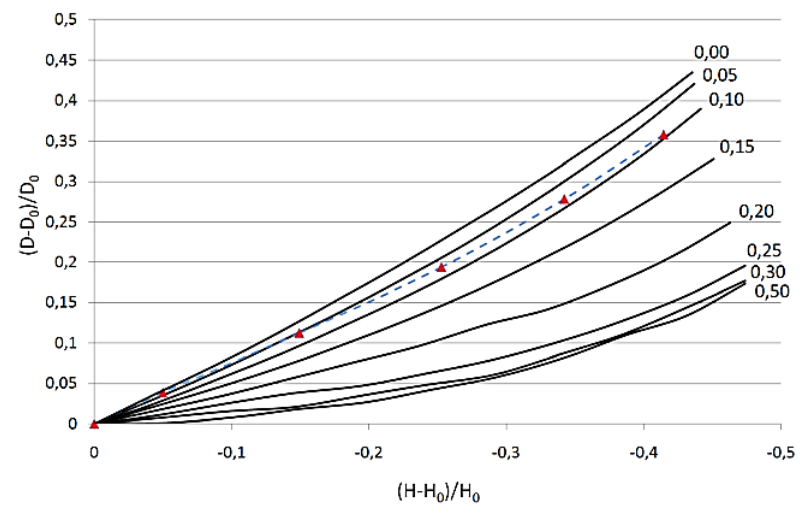

Slika 8. Poređenje eksperimentalno dobijene krive sa etalon dijagramom za ugao konusa $8^{\circ} 30^{\prime}$

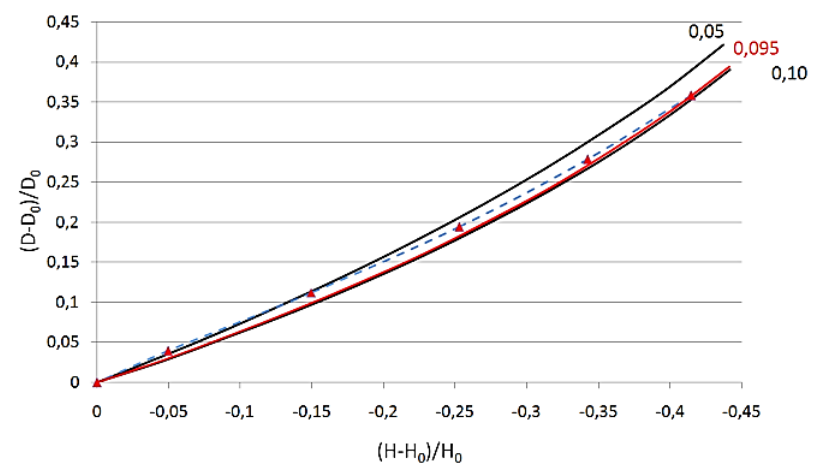

Slika 9. Određivanje koeficijenta trenja za ugao konusa $8^{\circ} 30^{\prime}$

Na slici 10. prikazana je komparacije eksperimentalno dobijene krive sa etalon dijagramom za uzorak ugla konusa $15^{\circ}$. I u ovom slučaju, za približnije određivanje koeficijenta trenja neophodno je bilo izvršiti dodatne simulacije za vrednosti koeficijenta trenja od $\mu=0,05$ do $\mu=0,10$. Nakon izvršenih dodatnih simulacije zaključeno je da se najbolje podudaranje eksperimentalno dobijene tačke sa kalibracionom krivom dobija pri vrednosti koeficijenta trenja $\mu=0,095$, kao što je prikazano na slici 11 . 


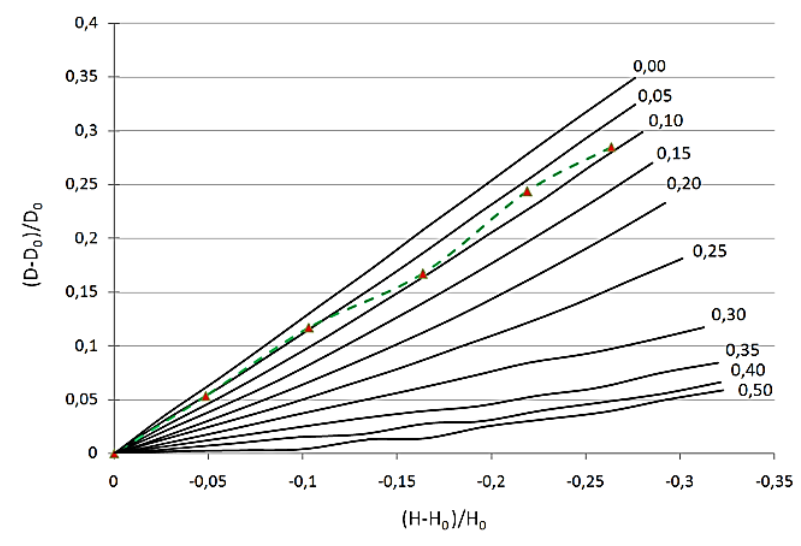

Slika 10. Poređenje eksperimentalno dobijene krive sa etalon dijagramom za ugao konusa $15^{\circ}$

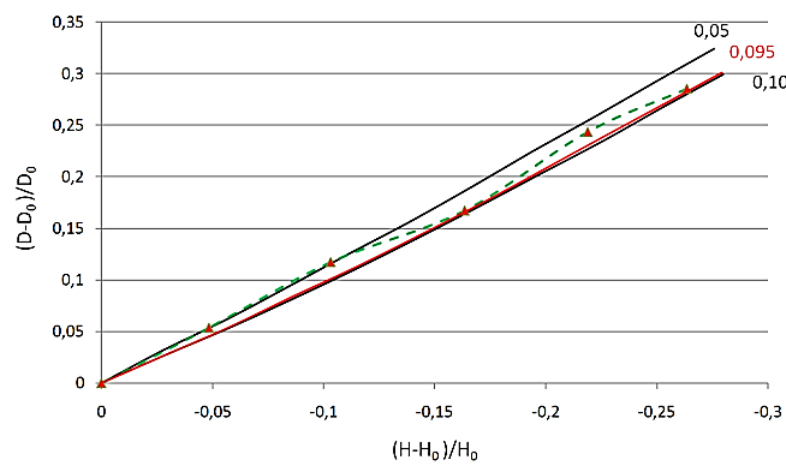

Slika 11. Određivanje koeficijenta trenja za ugao konusa $15^{\circ}$

Kao vrednost koeficijenta trenja, određenog metodom slobodnog sabijanja konusnog prstena, usvaja se $\mu=$ 0,095 .

\section{ZAKLJUČAK}

Metodom slobodnog sabijanja konusnih prstenova primenom dva različita tipa uzoraka, ugla konusa $8^{\circ} 30^{\prime}$ i $15^{\circ}$, određena je vrednost koeficijenta trenja u slučaju hladne obrade sa podmazivanjem uljem za material uzorka C45E. Za oba tipa uzoraka dobijena je vrednost koeficijenta trenja: $\mu=0,095$.

$\mathrm{S}$ obzirom da se $\mathrm{u}$ datim uslovima vrednost koeficijenta trenja kreće $u$ granicama od $\mu=0,08$ do $\mu=0,15$ dobijeno rešenje se smatra odgovarajućim.

\section{LITERATURA}

[1] H. Valberg, "Applied metal forming”, Cambridge, Cambridge University Press, 2010.

[2] V. Mandić, "Fizičko i numeričko modeliranje procesa obrade deformisanjem”, Kragujevac, Fakultet inženjerskih nauka, 2012.

[3] M. Plančak, Z. Car, M. Kršulja, D. Vilotić, I. Kačmarčik, D. Movrin, "Possibilities to measure contact friction in bulk metal forming", Tehnicki vjesnik, Vol. 19(4), pp. 727-723, 2012.

[4] M. Teller, A. Klubakov, M. Franzke, J. Lohmar, G. Hirt, "Extended Conical Tube-upsetting Test to Investigate the Evolution of Friction Conditions", Key Engineering Materials, Vol. 716, pp. 157-164, 2016.

[5] M. Teller, I. Ross, A. Temmler, R. Poprawe, S. Prünte, J. M.Schneider, G. Hirt, "Investigation of Friction Conditions in Dry Metal Forming of Aluminum by Extended Conical Tube-Upsetting Tests", Key Engineering Materials, Vol. 767, pp. 189-195, 2018.

\section{Kratka biografija:}

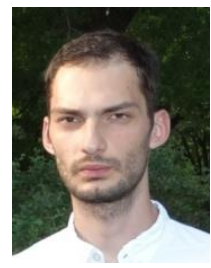

Nemanja Dačević rođen u Novom Sadu 1994. god. Osnovne studije završio je na Fakultetu tehničkih nauka u Novom Sadu 2017. godine. Master studije završava 2018. godine na Fakultetu tehničkih nauka u Novim Sadu na departmanu za Proizvodno mašinstvo, smer Savremene tehnologije oblikovanja materijala. kontakt: nemanjadacevic@gmail.com

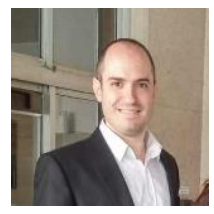

Marko Vilotić rođen u Novom Sadu 1979. god Diplomu osnovnih i magistarskih studija, kao i doktorat stekao je na Fakultetu tehničkih nauka. $\mathrm{Na}$ Fakultetu tehničkih nauka (Katedra za tehnologije oblikovanjem i inženjerstvo površina) radi kao docent. 